J. Lake Sci. (湖泊科学), 2015, 27(2):311-318

http: //www. jlakes. org. E-mail : jlakes@niglas.ac.cn

(c) 2015 by Journal of Lake Sciences

\title{
江苏滆湖北部湖区综合整治后夏季水体光环境研究”
}

何尚卫 ${ }^{1,2,3}$, 李 勇 ${ }^{2,3}$, 潘继征 ${ }^{1 * *}$, 高 亚 $^{1,2,3}$, 吴晓东 ${ }^{1,4}$

(1: 中国科学院南京地理与湖泊研究所湖泊与环境国家重点实验室, 南京 210008)

(2: 苏州科技学院环境科学与工程学院,苏州 215009)

(3: 江苏省环境科学与工程重点实验室,苏州 215009)

(4: 中国科学院大学,北京 100049)

摘 要: 选取滆湖为研究对象, 探究这一开放水体的北部湖区水体光环境是否有利于沉水植物的恢复. 通过对整治后的 2013 年夏季 $(7$ 月和 8 月) 滆湖北部整治湖区 ( $\mathrm{A}$ 湖区) 和临近未整治区 ( B 湖区) 水体光环境的监测, 发现在夏季 7 月 $\mathrm{A}$ 湖区透明度 $(\mathrm{SD})$ 平均达 $39 \mathrm{~cm}$, 显著高于 B 湖区, 同时 7 月 A 湖区 SD 较 8 月高. 夏季悬浮物和叶绿素 $\mathrm{a}(\mathrm{Chl} . \mathrm{a})$ 是影响水 体光环境的主要因子. 7 月两个湖区无机悬浮物的浓度差异是造成 $\mathrm{SD}$ 和 $K_{\mathrm{d}}$ 差异的原因; 7 月与 8 月 $\mathrm{A}$ 湖区 Chl. a 的浓度 差异, 是造成 A 湖区两个月份水体光环境差异的主要因素. 与整治时 (2009 年) 相比, 7 月水体光环境显著提高. 整治后 A 湖区水深的显著增加,在一定程度上不利于沉水植物的恢复.

关键词: 滆湖;综合整治;光;沉水植物

\section{Optical properties after multi-treatments in northern part of Lake Gehu, Jiangsu Province in summer}

HE Shangwei ${ }^{1,2,3}$, LI Yong ${ }^{2,3}$, PAN Jizheng ${ }^{1}$, GAO Ya ${ }^{1,2,3}$ \& WU Xiaodong ${ }^{1,4}$

(1: State Key Laboratory of Lake Science and Environment, Nanjing Institute of Geography and Limnology, Chinese Academy of Sciences, Nanjing 210008, P. R. China)

(2: School of Environmental Science and Engineering, Suzhou University of Science and Technology, Suzhou 215009, P. R. China)

(3: Key Laboratory of Environmental Science and Engineering of Jiangsu Province, Suzhou University of Science and Technology, Suzhou 215009, P. R. China)

(4: University of Chinese Academy of Sciences, Beijing 100049, P. R. China)

\begin{abstract}
In order to investigate whether the optical properties were benefit for the restoration of submerged plants in an open water in the northern of a shallow lake, Lake Gehu, we measured the influence factors of the underwater light environment in the areas which were with and/or without multi-treatments (area A and area B) in July and August, 2013. The results showed that the average secchi disk depth(SD) was $39 \mathrm{~cm}$ in July in area A, which was much higher than that in area B. The SD in July was also higher than that in August in area A. Suspended solids and chlorophyll-a (Chl. a) were the main factors of optical properties in summer. The significant difference of SD and $K_{\mathrm{d}}$ between the two areas in July was caused by the difference of inorganic suspended solids in two areas. The optical properties in area A also had a significant difference between July and August in 2013 , which was caused by the remarkable differences of Chl. a concentration in the two months. The underwater light environment of area A has improved significantly in July, compared with 2009 when it was under treatment. It will not benefit the restoration of submerged plants in area A as the depth has increased a lot.
\end{abstract}

Keywords: Lake Gehu; multi-treatments; light; submerged plants

* 国家水体污染控制与治理科技重大专项(2012ZX07101-007-01) 资助. 2014-04-03 收稿;2014-08-20 收修改稿. 何尚卫(1989 ), 男,硕士研究生;E-mail:763713334@ qq. com.

** 通信作者;E-mail:jzhpan@ niglas. ac. cn. 
在人类对湖泊越来越多的干扰下, 湖泊常由以大量沉水植物为代表的草型稳态湖泊演变为沉水植物大 量消失、藻类占主导优势的藻型稳态湖泊 ${ }^{[1]}$. 如何将衰退成藻型的湖泊或湖区恢复成草型湖泊或湖区, 以及 如何营造适合沉水植物生长的条件成为目前湖泊生态修复的研究热点. 影响沉水植物生长的主要因素有: 营养盐、底质、光、温度 ${ }^{[2-6]}$ 等. 目前多从营养盐和底质角度探索对沉水植物的影响, 如: 营养盐对沉水植物的 胁迫 ${ }^{[7]}$ 、底质对沉水植物生长的影响 ${ }^{[8]}$ 等. 而对于水体中的光环境, 这一影响沉水植物生长的重要因素, 以 及已经经过整治后的湖泊水体是否有所改善,却较少被关注. 影响光在水体中衰减的因子有: 水分子、悬浮 物、浮游植物和有色溶解有机质 $(\mathrm{CDOM})^{[9-11]}$, 其中水分子对光衰减可以看成本底值; 悬浮物可以对不同波 长的光造成衰减, 浮游植物可以选择性吸收光 ${ }^{[12-13]}$; CDOM 不仅吸收紫外光, 还能够吸收蓝光, 进而减少光 在水体中的传播 ${ }^{[14]}$, 在浅水湖泊中 CDOM 种类繁杂, 其对光衰减的贡献比较低,容易被光降解为小分子有 机物 ${ }^{[15]}$.

五里湖在开展生态工程后, 有国内学者曾对其水下光场进行了相关研究 ${ }^{[16]}$, 但其观测是在工程完成后 不久进行的, 且五里湖是一个相对封闭的水域. 滆湖位于常州武进和无锡宜兴境内 $\left(31^{\circ} 33^{\prime} \mathrm{N}, 119^{\circ} 49^{\prime} \mathrm{E}\right)$, 面 积 $164 \mathrm{~km}^{2}$, 于 2008 年至 2011 年对滆湖北部部分湖区进行了大范围综合整治, 以期为沉水植物重建提供必 要的条件. 整治的主要措施有: 前置库人湖污染负荷控制 ${ }^{[17]}$ 、底泥疏浚、水生植物净化水质、鲢鳙鱼非经典生 物操纵、大型仿生式机械捞藻等. 综合整治后, 整治湖区仍有污染不断进人, 且其同临近湖区并未完全隔离. 本文对综合整治后整治湖区的水体光环境对沉水植物重建的影响进行初步探究. 通过对 2009 年 7 月及 2013 年夏季 ( 7 月和 8 月) 整治湖区和临近未整治湖区水体光环境进行监测, 分析整治对水体光环境的改变 情况,并结合 2010 年定点的周年水深和透明度变化,提出综合整治对重建沉水植物的影响.

\section{1 材料和方法}

\section{1 采样点布设}

2013 年在滆湖北部湖区共布设 9 个采样点 (图 1), 其中综合整治的湖区共 6 个采样点 (1 6, 记为 A 湖 区), 临近的未进行整治湖区 3 个采样点 (7 9, 记为 B 湖区). A 湖区与 B 湖区之间大部分由人造堤坝所隔 离, 仅由 2 个宽约 $8 \mathrm{~m}$ 的通道相连接. 在综合整治时的 2009 年 7 月, 滆湖北部湖区共布设 5 个采样点 $(10 \sim$ $14), 2010$ 年在滆湖东岸生态修复区的外敞水区进行定点周年水深和透明度 (SD) 的测量.

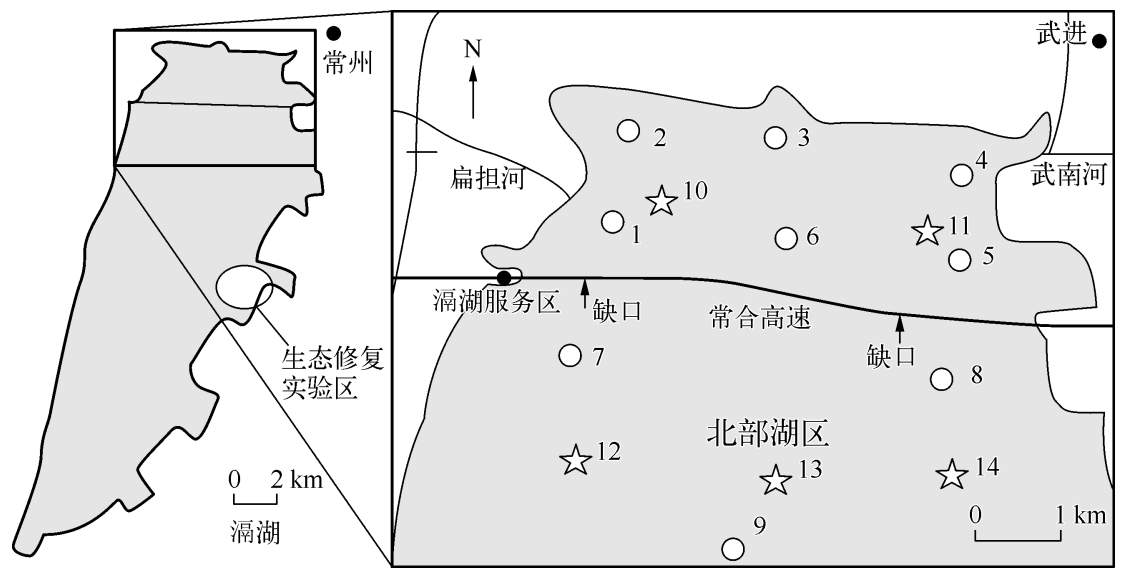

图 1 滆湖北部采样点

Fig. 1 Sampling sites in the north Lake Gehu

\section{2 测量方法及数据处理}

2009 年 7 月对样点 $10 \sim 14$ 进行光合有效辐射 (PAR) 测定, 2013 年 7 月 23 日对北部 9 个采样点进行 SD 和 PAR 测定, 8 月 28 日仅对 A 区 6 个点进行 SD 和 PAR 测定. 测定时间均在 $11: 00-14: 00$ 之间, 天气晴 朗. PAR 采用 XR-620CTD 多参数水质剖面仪 (RBR Ltd., Canada) 每隔 $2 \mathrm{~s}$ 连续自动进行测定记录 ${ }^{[9]}$, SD 采 
用直径为 $30 \mathrm{~cm}$ 的塞氏盘进行测量, 用水深仪记录水深.

水体中的光环境常用 SD、PAR 衰减系数 $\left(K_{\mathrm{d}}\right)$ 和真光层深度 $\left(Z_{\mathrm{eu}}\right)$ 来描述 ${ }^{[9-11,18]}$ :

$$
\begin{gathered}
K_{\mathrm{d}}=-\frac{1}{Z} \ln \frac{E(Z)}{E(0)} \\
Z_{\text {eu }}=4.605 / K_{\mathrm{d}}
\end{gathered}
$$

式中, $Z$ 为从湖面到测量处的深度, $E(\mathrm{Z}) 、 E(0)$ 分别为深度为 $Z$ 处、 $0 \mathrm{~m}$ 处的 PAR 强度, $K_{\mathrm{d}}$ 值通过对不同深 度水下 PAR 强度进行回归得到 $\left(R^{2} \geqslant 0.95, N \geqslant 8, N \text { 为拟合深度个数 }\right)^{[10]}$.

用聚乙烯瓶同步采集各样点表层 $0 \sim 0.5 \mathrm{~m}$ 处水样, 快速带回实验室进行相关水质参数的测定. 叶绿素 $a\left(\right.$ Chl. a) 采用 $90 \%$ 丙酮浸提法测定 ${ }^{[19]}$; 悬浮物 ( SS)、无机悬浮物 ( ISS)、有机悬浮物 ( OSS ) 测量采用称重 法 $^{[20]}$; CDOM 采用紫外一可见分光光度法, 具体操作为: 经 $0.22 \mu \mathrm{m}$ 的 Millpore 膜的水样, 用 UV100 (天津冠 泽科技有限公司) 分光光度计光谱扫描测量吸光度. 以纯水作为参考, $1 \mathrm{~nm}$ 为步长, 扫描波段为 $200 \sim$ $800 \mathrm{~nm}$. CDOM 用 $440 \mathrm{~nm}$ 波长处的吸收系数来表示 ${ }^{[14,21]}$ :

$$
a_{\mathrm{CDOM}}(\lambda)=2.303 A(\lambda) / r-a(700) \cdot \lambda / 700
$$

式中, $\lambda$ 为波长, $a_{\mathrm{CDOM}}(\lambda)$ 为波长 $\lambda$ 时 $\mathrm{CDOM}$ 的吸收系数, $A(\lambda)$ 为波长 $\lambda$ 时的吸光度, $r$ 为光程路径 $(\mathrm{m})$.

数据采用 Excel 2003 及 SPSS 16.0 处理.

\section{2 结果}

\section{1 水深和透明度改变情况}

在 2010 年滆湖东岸生态修复区的外敞水区水深和透明度呈现出显著的季节变化 (图 2). 在春、夏季滆 湖水深较秋、冬季高, 水深最大值约为 $1.90 \mathrm{~m}$, 周年平均水深 $1.20 \mathrm{~m}$. 经过综合整治的 $\mathrm{A}$ 湖区, 在 2013 年 8 月几个点位平均水深为 $2.7 \mathrm{~m}, \mathrm{~B}$ 湖区几个点位平均水深仅为 $1.30 \mathrm{~m}$ (图 3), 可见综合整治显著增加了 $\mathrm{A}$ 湖 区水深.

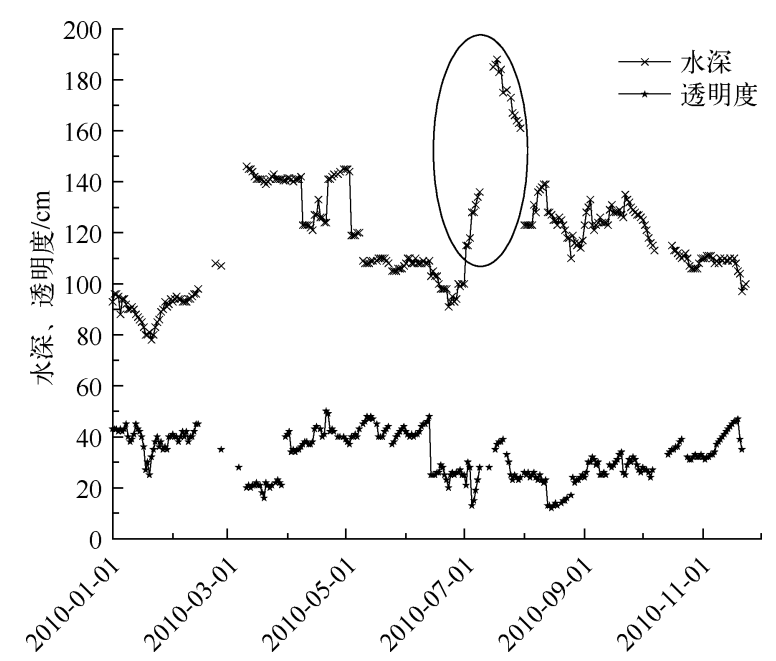

图 22010 年滆湖生态修复区外的水深和透明度变化

Fig. 2 Variations of water depth and transparency out of the eco-remediation zone in 2010

在生态修复区外, 2010 年夏、秋季 SD 显著低于冬、春季, 周年平均值为 $33 \mathrm{~cm}$ (图 2). 2013 年 7 月 A 湖 区 $\mathrm{SD}$ 为 $38 \sim 46 \mathrm{~cm}$, 平均值为 $39 \mathrm{~cm}$, 显著大于 $(P<0.05) \mathrm{B}$ 湖区 $\mathrm{SD}$ 平均值 $(20 \mathrm{~cm}) .8$ 月 A 湖区 $\mathrm{SD}$ 变化范 围为 $19 \sim 23 \mathrm{~cm}$, 平均值为 $21 \mathrm{~cm}$, 低于 7 月 $\mathrm{A}$ 湖区 $(P<0.01$, 图 3$)$. 


\section{2 光衰减系数情况}

2013 年 7 月 $\mathrm{A}$ 湖区所有点位的 $K_{\mathrm{d}}$ 变化范围为 $1.96 \sim 2.76 \mathrm{~m}^{-1}$, 平均值为 $2.47 \mathrm{~m}^{-1}$; 7 月 $\mathrm{B}$ 湖区 $K_{\mathrm{d}}$ 变化 范围为 $3.46 \sim 4.42 \mathrm{~m}^{-1}$, 平均值为 $3.97 \mathrm{~m}^{-1}$, 显著大于 A 湖区 $(P<0.05) .2013$ 年 8 月 A 湖区的 $K_{\mathrm{d}}$ 变化范 围为 $2.81 \sim 3.62 \mathrm{~m}^{-1}$, 平均值为 $3.28 \mathrm{~m}^{-1}$, 显著大于 2013 年 7 月的 $K_{\mathrm{d}}(P<0.01)$. 同 2009 年 7 月相比, 2013 年 7 月 $\mathrm{A}$ 湖区 $K_{\mathrm{d}}$ 显著小于前者 $(P<0.01)$, 而 $\mathrm{B}$ 湖区 $K_{\mathrm{d}}$ 与整治时相比无显著差异 $($ 图 4$)$, 说明综合整治显 著提高了夏季 $(7$ 月) A 湖区水体光环境.

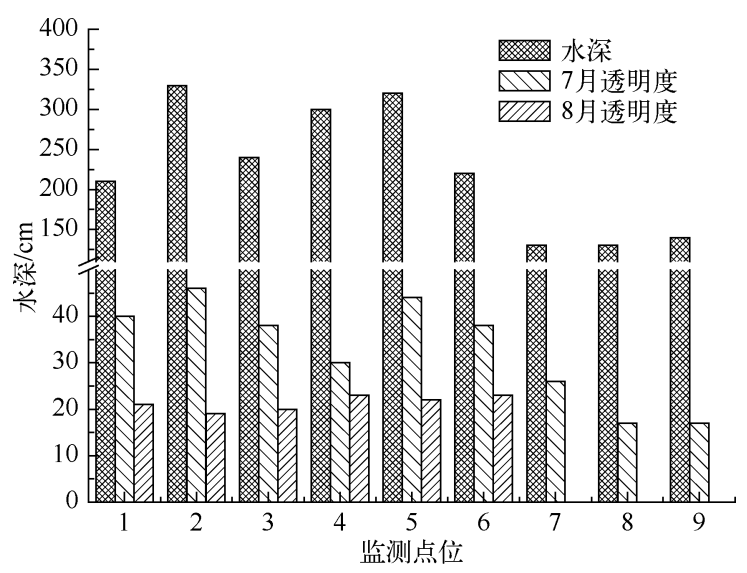

图 32013 年夏季各采样点水深和透明度

Fig. 3 The values of depth and SD at different samping sites in the summer of 2013

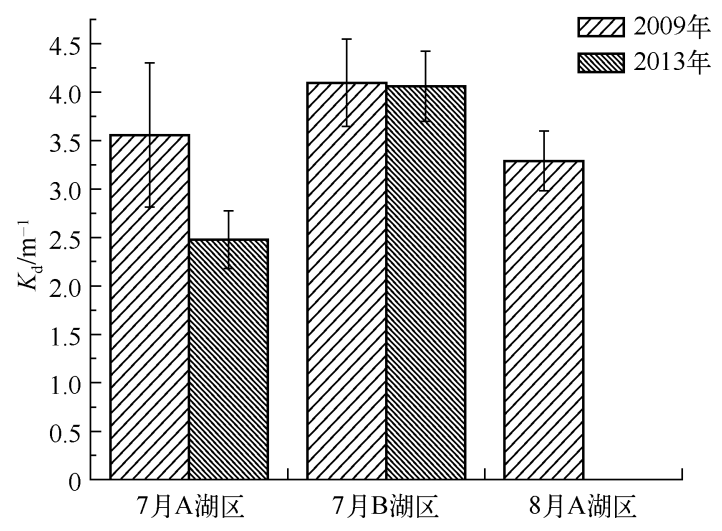

图 42009 年 7 月、2013 年 7 月及 8 月 滆湖北部湖区 $K_{\mathrm{d}}$ 值

Fig. 4 The value of $K_{\mathrm{d}}$ in the north Lake Gehu in July of 2009 and July, August of 2013

\section{3 夏季不同衰减因子情况}

通过滆湖北部 A、B 两湖区夏季 3 个影响光衰减因子的对比研究, 可以看出 A、B 两湖区各光衰减因子 对水体光环境的影响情况 (图 5 ).

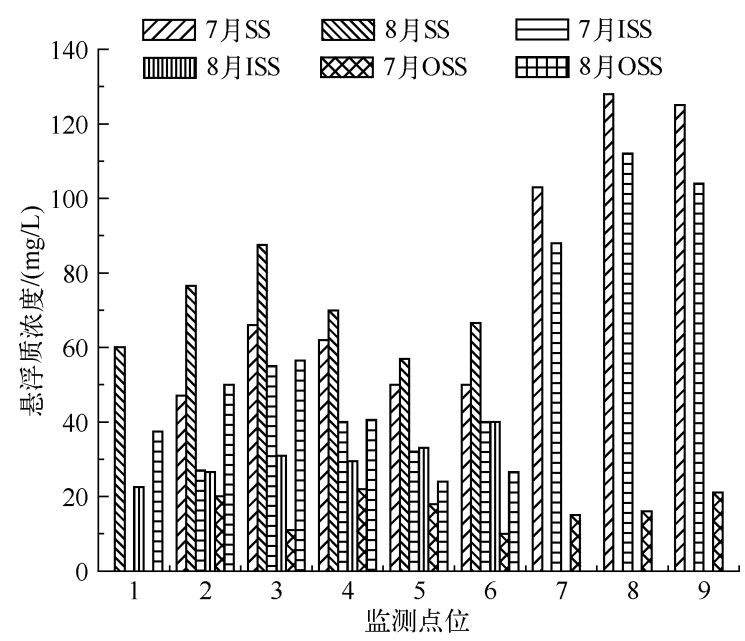

图 5 各采样点 7 月及 8 月 SS、ISS、OSS 浓度值

Fig. 5 Concentrations of SS, ISS and OSS in July and August of different sampling sites 
2.3.1 SS 变化情况 $\mathrm{A}$ 湖区的 7 月 $\mathrm{SS}$ 变化范围为 $47 \sim 66 \mathrm{mg} / \mathrm{L}$, 平均值为 $55 \mathrm{mg} / \mathrm{L}$; B 湖区的 $\mathrm{SS}$ 变化范围为 $103 \sim 128 \mathrm{mg} / \mathrm{L}$, 平均值为 $118.7 \mathrm{mg} / \mathrm{L} . \mathrm{A}$ 湖区 8 月 $\mathrm{SS}$ 变化范围为 $57 \sim 87.5 \mathrm{mg} / \mathrm{L}$, 平均值为 $69.6 \mathrm{mg} / \mathrm{L} .7$ 月 A、B 湖区 SS 差异性显著 $(P<0.05)$, 同时 A 湖区 7 月和 8 月 SS 值差异也显著 $(P<0.05)$.

$\mathrm{SS}$ 由 ISS 和 OSS 组成. 7 月 A 湖区的 ISS 变化范围为 $27 \sim 55 \mathrm{mg} / \mathrm{L}$, 平均值为 $38.8 \mathrm{mg} / \mathrm{L}$; OSS 变化范围 为 $10 \sim 22 \mathrm{mg} / \mathrm{L}$, 平均值为 $16.2 \mathrm{mg} / \mathrm{L}$. B 湖区的 ISS 变化范围为 $88 \sim 112 \mathrm{mg} / \mathrm{L}$, 平均值为 $101.3 \mathrm{mg} / \mathrm{L}$; OSS 变化范围为 $16 \sim 21 \mathrm{mg} / \mathrm{L}$, 平均值为 $17.3 \mathrm{mg} / \mathrm{L} . \mathrm{A} 、 \mathrm{~B}$ 两湖区 ISS 有显著差异 $(P>0.05)$, 而 OSS 没有显著差 异 $(P>0.05) .8$ 月 A 湖区 ISS 变化范围为 $23 \sim 40 \mathrm{mg} / \mathrm{L}$, 平均值为 $30.7 \mathrm{mg} / \mathrm{L}$, 与 7 月 A 湖区 ISS 相比差异 不显著 $(P>0.05)$; OSS 变化范围为 $24 \sim 57 \mathrm{mg} / \mathrm{L}$, 平均值为 $39.2 \mathrm{mg} / \mathrm{L}$, 与 7 月 A 湖区 OSS 相比差异显著 $(P<0.01)$.

2.3.2 Chl. a 变化情况 7 月 A 湖区采样点 4 及其周围出现大面积藻团, 经现场观测是由 B 湖区的藻团在风 力的作用下经隔断堤坝中的缺口涌向 $\mathrm{A}$ 湖区, 从缺口处到采样点 4 的直线距离的两边有大量藻类覆盖. 7 月 $\mathrm{A}$ 湖区的 Chl. $\mathrm{a}$ 的变化范围为 $14.86 \sim 118.53 \mu \mathrm{g} / \mathrm{L}$, 平均值为 $49.13 \mu \mathrm{g} / \mathrm{L}$; B 湖区的 Chl. a 变化范围为 $65.71 \sim 81.24 \mu \mathrm{g} / \mathrm{L}$, 平均值为 $73.46 \mu \mathrm{g} / \mathrm{L} ; 8$ 月 A 湖区在风力作用下, 湖面也出现大面积的藻团, Chl. a 变化 范围为 $36.45 \sim 175.44 \mu \mathrm{g} / \mathrm{L}$, 平均值为 $94.06 \mu \mathrm{g} / \mathrm{L}$, 是 7 月 A 区平均值的 2 倍左右 (图 6 ).

2.3.3 CDOM 变化情况 在滆湖北部湖区, CDOM 对光的吸收呈现出显著的空间差异, 7 月 A 湖区 $a_{\mathrm{CDOM}}(440)$ 最小值为 $0.92 \mathrm{~m}^{-1}$, 最大值为 $3.91 \mathrm{~m}^{-1}$, 平均值为 $2.53 \mathrm{~m}^{-1} ; \mathrm{B}$ 湖区最小值为 $2.53 \mathrm{~m}^{-1}$, 最大值 为 $3.91 \mathrm{~m}^{-1}$, 平均值 $\left(2.91 \mathrm{~m}^{-1}\right)$ 较 $\mathrm{A}$ 湖区大, 但两者之间没有显著差异 $(P>0.05) .8$ 月 $\mathrm{A}$ 湖区 $a_{\mathrm{CDOM}}(440)$ 变化范围为 $1.38 \sim 2.30 \mathrm{~m}^{-1}$, 平均值为 $1.65 \mathrm{~m}^{-1}$, 是 7 月平均值的 $56.7 \%$, 但差异不显著 $(P>0.05)$ (图 6 ).
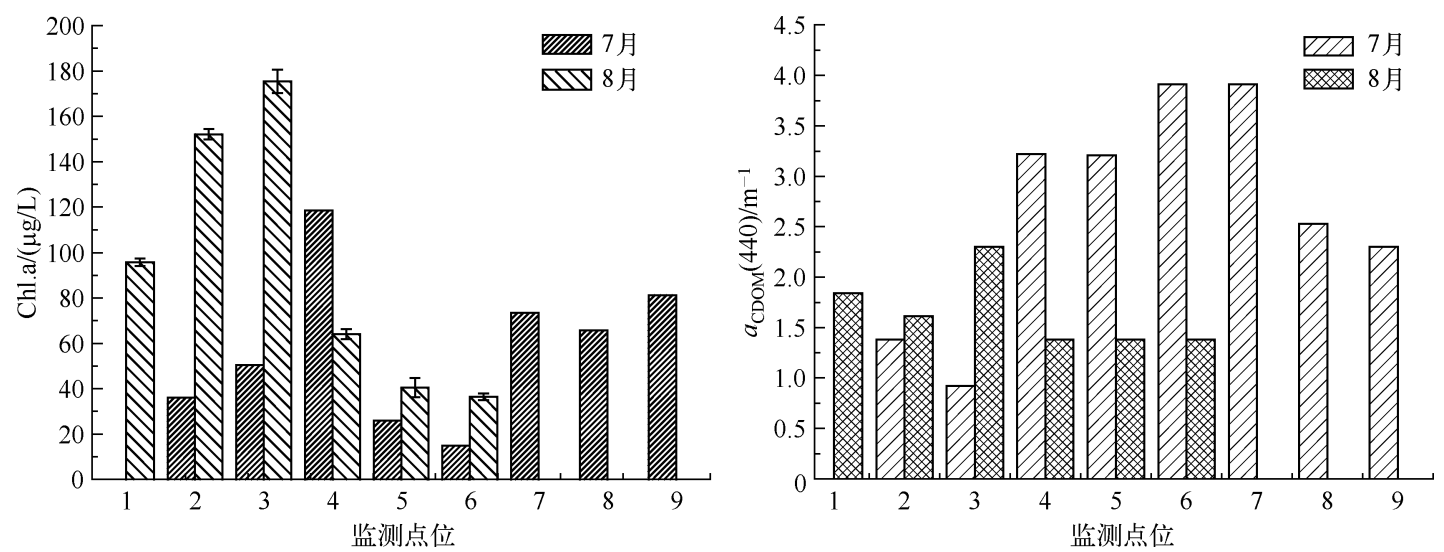

图 6 各采样点 7 月及 8 月 Chl. a 和 $a_{\mathrm{CDOM}}(440)$ 值

Fig. 6 The values of Chl. a and $a_{\text {CDOM }}(440)$ in July and August of different sampling sites

\section{3 讨论}

\section{1 水体光环境与相关因子之间的关系}

湖泊底泥表面易悬浮颗粒物在综合整治时被大量移除, 且 A、B 两湖区之间大部分被人造堤坝所隔离, 起到类似消浪和围隔的功能, 大幅降低了底泥再悬浮的能力 ${ }^{[22]}$, 减少了颗粒物对光的吸收和散射, 进而提高 $\mathrm{SD}$, 减小 $K_{\mathrm{d}}$, 但底泥疏浚这一措施在治理湖泊水体中的施用,具有较大的争议 ${ }^{[23]}$.

对夏季滆湖 A 湖区 SS、ISS 和 $K_{\mathrm{d}}$ 之间关系进行拟合:

$$
\begin{array}{cccc}
K_{\mathrm{d}}=0.022 \mathrm{SS}+1.505 & R^{2}=0.684 & n=14 & P<0.05 \\
K_{\mathrm{d}}=0.015 \mathrm{ISS}+2.369 & R^{2}=0.446 & n=14 & P<0.01
\end{array}
$$

夏季滆湖水体的 SS、ISS 和 $K_{\mathrm{d}}$ 均有一定的相关性 (公式(4)、(5)). 同整治时 ${ }^{[24]}$ 相同, 整治后 SS 也是影 响夏季水体光环境的重要因子. 在 7 月 B 湖区的水体光环境显著较 A 湖区差, A、B 湖区的 Chl. a 及 CDOM 
均无显著差异, 而 B 湖区 ISS 平均值却是 A 湖区 ISS 平均值的 2.6 倍左右, 表明 SS 中的 ISS 是造成 SD 和 $K_{\mathrm{d}}$ 差异的原因之一.

夏季大面积藻团漂浮在滆湖水体表层, 可以吸收大量可见光, 导致 SD 的降低和 $K_{\mathrm{d}}$ 的增大. 7 月 B 湖区 的藻类在风力的作用下经过隔断堤坝缺口而迁移至 A 湖区, 致使采样点 4 的透明度较 A 湖区其他点位低. 7 月和 8 月 A 湖区 OSS、Chl. a 与 SD 之间呈一定的线性相关(公式(6)、(7)), 但 $K_{\mathrm{d}}$ 和 OSS、Chl. a 之间线性关 系并不显著 $(P=0.086 、 0.522)$.

$$
\begin{array}{cccc}
\mathrm{SD}=-10.39 \ln (\mathrm{OSS})+60.034 & R^{2}=0.301 & n=14 & P<0.05 \\
\mathrm{SD}=-9.274 \ln (\text { Chl. a })+65.398 & R^{2}=0.408 & n=14 & P<0.05
\end{array}
$$

2013 年 7 月和 8 月 A 湖区 ISS、CDOM 都无显著差异, OSS 有差异显著, 且 OSS 和 Chl. a 之间显著相关 $\left(R^{2}=0.603, n=14, P<0.001\right)$, 故可以认为 Chl. a 的差异是造成滆湖北部 A 湖区 7 月和 8 月 SD 差异的原 因. 通过减少水体中浮游植物的量, 进而提高 SD, 可以为沉水植物的重建提供所需的光环境, 如 Pan 等 ${ }^{[25]}$ 用 壳聚糖修饰粘土絮凝沉淀水体中大量的浮游植物至底泥表面, 提高了 $\mathrm{SD}$, 在 4 个月后便成功恢复了沉水 植物.

夏季水体中藻类死亡后会释放出 CDOM, 在一定时间内可以被微生物降解. 藻类所产生的 CDOM 和 Chl. a 之间有一定的线性关系 ${ }^{[26]}$, 但在本研究中却没有发现 Chl. a 和 CDOM 有相关性 $(P>0.05)$, 可能与藻 类尚未大量死亡有关. 同时 7 月和 8 月的 CDOM 和 SD 及 $K_{\mathrm{d}}$ 之间无显著线性相关关系 $(P>0.05)$.

\section{2 综合整治对沉水植物生长的影响}

沉水植物在水体中的最大生长深度与水深有显著的相关关系 ${ }^{[27-32]}$, 水深的增加使得到达湖底的光程增 加, 从而减少了沉水植物生长所需要的光, 进而对沉水植物的生长产生不利影响, 如在洱海水深超过 $2.5 \mathrm{~m}$ 的地方, 将限制沉水植物的生长 ${ }^{[33]}$. 在综合整治后, 尤其是实施底泥疏浚后, 大量的内源污染物从湖泊底泥 中移除,降低了内源污染释放的能力 ${ }^{[34-35]}$, 但同时也改变了湖区的底质和水深( 图 3 ).

对沉水植物已消失的水体再进行沉水植物的恢复, 其前提是 SD 必须达到一定的要求 ${ }^{[36]}$, 通常沉水植 物在深度为 SD 的 2 倍处较容易恢复 ${ }^{[23,27]} .2013$ 年夏季 (7、8 月) A 湖区沉水植物的容易恢复深度分别为 80 $\mathrm{cm}$ 及 $40 \mathrm{~cm}$ 左右, 这明显小于综合整治后 $\mathrm{A}$ 湖区的平均水深 (图 3). 从沉水植物生长的限制因子光角度而 言, 在 2013 年夏季除人工堆积的小岛附近, A 湖区大部分难以满足沉水植物生长的需求, 与现场观测到只有 人工小岛附近有少量金鱼藻生长相符合.

滆湖秋、冬季光环境较夏季好 (图 2) ${ }^{[24]}$. 从光角度而言, 秋、冬季沉水植物较容易重建, 重建的沉水植物 还可以为春季其他沉水植物的生长提供稳定的前驱水体光环境, 如 2010 年秋季滆湖东岸生态修复区重建 的菹草群落, 稳定了生态修复区内的水体透明度 ${ }^{[37]}$. 当考虑到湖区水体的使用功能时, 恢复全部沉水植物是 没有必要的, 因其会对航运等产生影响 ${ }^{[38-39]}$, 同时过多覆盖面积与适宜覆盖面积的沉水植物相比, 如金鱼 藻, 对水质的净化也无显著差异 ${ }^{[40]}$. 故在满足草型稳态和其他使用需求之间, 沉水植物在水体中需达到一个 协调的覆盖率 ${ }^{[38]}$.

从光衰减因子的角度而言, $\mathrm{SS}$ 是光衰减的重要因子, 如当 $\mathrm{SS}$ 超过 $50 \mathrm{mg} / \mathrm{L}$ 时, 沉水植物较难生长 ${ }^{[41]}$. 在综合整治后的 2013 年夏季 7、8 月份, A 湖区 SS 达 $47 \sim 87.5 \mathrm{mg} / \mathrm{L}$, 可见 SS 浓度是沉水植物在 A 湖区生长 的限制因子之一. 因此可以考虑从人工堆造的小岛附近隔离部分湖区, 种植漂浮植物, 短期内迅速提高 $\mathrm{SD}^{[42]}$, 随后移除漂浮植物, 引种沉水植物, 种植的沉水植物可以优先考虑较耐受 $\mathrm{SS}$ 的穗花狐尾藻 ${ }^{[43]}$.

\section{4 结论}

滆湖北部整治湖区在综合整治后, 夏季 7 月水体光环境与整治时相比显著改善. 在 2013 年 7 月滆湖北 部整治湖区与未整治湖区水体的 SS 中 ISS 显著不同, 是造成 2 个湖区 SD 和 $K_{\mathrm{d}}$ 显著差异的原因; 在 7 月和 8 月整治湖区 Chl. a 浓度的显著差异是造成这两个月水体 SD 差异显著的原因. 7 月和 8 月滆湖北部湖区 CDOM 对水体光环境无显著影响. 夏季在风力的作用下, 临近未整治湖区的藻类易飘移至北部整治湖区, 从 而影响了整治湖区水下光环境的稳定性. 底泥疏浚使整治湖区水深显著增加, 导致了光程的增加, 在一定程 


\section{度上不利于整治湖区沉水植物的恢复.}

致谢: 初稿得到尚丽霞、徐伟伟的相关修改意见,在此对他们致以诚挚的感谢.

\section{5 参考文献}

[ 1 ] Sagrario G, María A, Jeppesen E et al. Does high nitrogen loading prevent clear-water conditions in shallow lakes at moderately high phosphorus concentrations? Freshwater Biology, 2005, 50 ( 1 ):27-41.

[ 2 ] Bornette G, Puijalon S. Response of aquatic plants to abiotic factors: a review. Aquatic Sciences, 2011, 73(1):1-14.

[ 3 ] Ciurli A, Zuccarini P, Alpi A. Growth and nutrient absorption of two submerged aquatic macrophytes in mesocosms, for reinsertion in a eutrophicated shallow lake. Wetlands Ecology and Management, 2009, 17(2) :107-115.

[ 4 ] Wang S, Jin X, Zhao H et al. Phosphate biosorption characteristics of a submerged macrophyte Hydrilla verticillata. Aquatic Botany, 2008, 89 (1) :23-26.

[ 5 ] Rattray MR, Howard WC, Brown JMA. Sediment and water as sources of nitrogen and phosphorus for submerged rooted aquatic macrophytes. Aquatic Botany, 1991, 40(3):225-237.

[ 6 ] Zhang M, Cao T, Ni L et al. Light-dependent phosphate uptake of a submersed macrophyte Myriophyllum spicatum L. Aquatic Botany, 2011, 94(4) :151-157.

[ 7 ] 宋玉芝,杨美玖,秦伯强. 苦草对富营养化水体中氮磷营养盐的生理响应. 环境科学, 2011,32(9):2569-2575.

[8] 霍耀东, 邹联沛, 温从汉等. 水体底质中磷对菹草生长的影响. 环境科学与技术, 2011,34(12):14-17.

[ 9 ] Lin SY, Zou T, Gao HW et al. The vertical attenuation of irradiance as a function of turbidity: a case of the Huanghai (Yellow) Sea in spring. Acta Oceanologica Sinica, 2009, 28(5) :66-75.

[10] 时志强,张运林,殷 燕等. 博斯腾湖夏季水下光场特征分析及影响因素探讨. 环境科学学报,2012,32 (12): 2969-2977.

[11] 朱宜平,张海平. 小型富营养水体光合有效辐射衰减特性分析. 环境污染与防治, 2011,33(3):65-68.

[12] Ciotti AM, Lewis MR, Cullen JJ. Assessment of the relationships between dominant cell size in natural phytoplankton communities and the spectral shape of the absorption coefficient. Limnology and Oceanography, 2002, 47(2):404-417.

[13] 王 金金,张运林. 微囊藻和栅列藻吸收与散射特性的实验研究. 海洋湖沼通报,2007,( B12):82-90.

[14] 张运林, 吴生才,秦伯强等. 太湖梅梁湾有色可溶性有机物对光的吸收. 中国环境科学,2004,24(4):405-409.

[15] 冯 胜,张运林,秦伯强. 太湖梅梁湾有色可溶性有机物的光化学降解. 中国环境科学,2006,26(4):404-408.

[16] 张运林, 陈开宁, 秦伯强. 五里湖南岸生态示范工程对水下光场的改善效果研究. 水科学进展,2007,18(1):86-94.

[17] 张毅敏,段金程, 昆建颖等. 河口前置库系统在滆湖富营养化控制中的应用研究. 生态与农村环境学报,2013,29 (3) : 273-277.

[18] 张运林,秦伯强, 胡维平等. 太湖典型湖区真光层深度的时空变化及其生态意义. 中国科学: D 辑, 2006,36 (3) : 287-296.

[19］韩桂春,谷 丰,张忠臣. 淡水中叶绿素 a 测定方法的探讨. 中国环境监测,2005,21(1):55-57.

[20］国家环境保护总局. 水和废水监测分析方法:第四版. 北京:中国环境科学出版社,2002:105-108.

[21] 乐成峰, 李云梅, 张运林等. 太湖水色因子空间分布特征及其对水生植物光合作用的影响. 应用生态学报,2007,18 (11) :2491-2496.

[22] Huang P, Liu Z. The effect of wave-reduction engineering on sediment resuspension in a large, shallow, eutrophic lake ( Lake Taihu). Ecological Engineering, 2009, 35(11) :1619-1623.

[23] 誉培民,王国祥,胡春华等. 底泥疏浚能控制湖泊富营养化吗? 湖泊科学,2000,12(3):269-279.

[24] 何尚卫,李 勇,赵海光等. 滆湖水体光学性质初步研究. 湖泊科学,2014,26(5):707-712.

[25] Pan G, Yang B, Wang D et al. In-lake algal bloom removal and submerged vegetation restoration using modified local soils. Ecological Engineering, 2011, 37(2):302-308.

[26] Zhang Y, van DMA, Liu M et al. The contribution of phytoplankton degradation to chromophoric dissolved organic matter ( CDOM) in eutrophic shallow lakes: field and experimental evidence. Water Research, 2009, 43 (18):4685-4697.

[27] Sand JK, Pedersen NL, Thorsgaard I et al. 100 years of vegetation decline and recovery in Lake Fure, Denmark. Journal of Ecology, 2008, 96(2):260-271.

[28 ] May L, Carvalho L. Maximum growing depth of macrophytes in Loch Leven, Scotland, United Kingdom, in relation to his- 
torical changes in estimated phosphorus loading. Hydrobiologia, 2010, 646(1):123-131.

[29] Hudon C, Lalonde S, Gagnon P. Ranking the effects of site exposure, plant growth form, water depth, and transparency on aquatic plant biomass. Canadian Journal of Fisheries and Aquatic Sciences, 2000, 57 (S1 ) :31-42.

[30] Canfield DE, Langeland KA, Linda SB et al. Relations between water transparency and maximum depth of macrophyte colonization in lakes. Journal of Aquatic Plant Management, 1985, 23(1) :25-28.

[31] Søndergaard M, Phillips G, Hellsten S et al. Maximum growing depth of submerged macrophytes in European lakes. Hydrobiologia, 2013, 704(1):165-177.

[32] 任久长, 周 红. 滇池光照强度的垂直分布与沉水植物的光补偿深度. 北京大学学报: 自然科学版, 1997, 33 (2): 211-214.

[33] Zhu G, Li W, Zhang M et al. Adaptation of submerged macrophytes to both water depth and flood intensity as revealed by their mechanical resistance. Hydrobiologia, 2012, 696 (1):77-93.

[34] 陈 超,钟继承,范成新. 湖泊疏浚方式对内源释放影响的模拟研究. 环境科学, 2013,34(10):3872-3878.

[35] Reddy KR, Fisher MM, Wang Y et al. Potential effects of sediment dredging on internal phosphorus loading in a shallow, subtropical lake. Lake and Reservoir Management, 2007, 23(1) :27-38.

[36] Moss B. Engineering and biological approaches to the restoration from eutrophication of shallow lakes in which aquatic plant communities are important components. Biomanipulation Tool for Water Management, 1990, 61:367-377.

[37] 吴晓东,潘继征, 李文朝等. 滆湖东岸生态修复试验区的水质净化效果. 生态与农村环境学报, 2013,29(3): 284-289.

[38] Van NEH, Scheffer M, Van den BMS et al. Aquatic macrophytes: restore, eradicate or is there a compromise? Aquatic Botany, 2002, $72(3): 387-403$.

[39] Hilt S, Gross EM, Hupfer M et al. Restoration of submerged vegetation in shallow eutrophic lakes-A guideline and state of the art in Germany. Limnologica-Ecology and Management of Inland Waters, 2006, 36(3):155-171.

[40] Dai Y, Jia C, Liang W et al. Effects of the submerged macrophyte Ceratophyllum demersum L. on restoration of a eutrophic waterbody and its optimal coverage. Ecological Engineering, 2012, 40:113-116.

[41] Havens KE. Submerged aquatic vegetation correlations with depth and light attenuating materials in a shallow subtropical lake. Hydrobiologia, 2003, 493 (1/2/3):173-186.

[42] 成小英, 王国祥, 緩培民等. 冬季富营养化湖泊中水生植物的恢复及净化作用. 湖泊科学, 2002,14(2):139-144.

[43] 李 强, 王国祥, 王文林等. 悬浮泥沙水体对穗花狐尾藻 (Myriophyllum spicatum L.) 光合苂光特性的影响. 湖泊科 学, 2007,19(2):197-203. 